\title{
Students' perceptions of plagiarism and relevant policies in Cyprus
}

\author{
Angelika I Kokkinaki ${ }^{1 *}$, Catherine Demoliou ${ }^{2}$ and Melpo lakovidou ${ }^{3}$
}

\author{
* Correspondence: \\ kokkinaki.a@unic.ac.cy \\ ${ }^{1}$ Department of Management and \\ MIS, University of Nicosia, Nicosia, \\ Cyprus \\ Full list of author information is \\ available at the end of the article
}

\begin{abstract}
Background: Effective plagiarism deterrence in the Republic of Cyprus, requires the identification of any gaps, best practices and case studies relating to plagiarism across the Higher Educational Institutions in the country. This paper discusses the findings of the first research conducted among university students and faculty in Cyprus and focuses on students' awareness of and perceptions towards academic plagiarism.

Methodology: The research instrument for students was initially designed based on experts' feedback, as part of the IPPHEAE project. It was translated into the national language and pilot tested. The questionnaire included 33 questions of the following types: i) open-ended questions; ii) multiple choice questions in two variations: those requiring mutually exclusive options and single response and those permitting multiple selected answers and iii) Likert-type scale questions. The target population of the study included all students, undergraduate and graduate, pursuing an academic degree, in public and private universities in Cyprus. A total of 318 correctly completed questionnaires were collected.
\end{abstract}

Results: It is clear from the findings of this study that there is a need for a clear and uniform definition and understating of the terms "plagiarism" and "academic dishonesty". There is also a need to develop mechanisms for communicating these definitions both to students and to faculty, in addition to ensuring that these terms have been understood. In the setting up of policies, procedures and penalties for plagiarism and academic dishonesty, it is necessary to have uniformity and consistency in both implementation and especially in the imposition of penalties. The results also indicate that the use of tools, such as software for the detection or discourage of plagiarism, would definitely contribute positively to reducing plagiarism.

Conclusions: Findings and recommendations outlined in this paper have been included to a national report distributed to interested stakeholders and it may contribute towards improved perceptions of students regarding plagiarism and relevant policies in Cyprus.

Keywords: Anti-plagiarism; Policies; Procedures; Perceptions

\section{Background}

It could be argued that easy accessibility to online educational resources and to scientific publications has facilitated academic plagiarism, which is defined in (Carroll 2007) as "passing off someone else's work, whether intentionally or unintentionally, as your own for your own benefit". The increased number of identified cases at Higher Educational Institutions (HEIs) raises concerns among academic faculty and administrators as well as

(c) 2015 Kokkinaki et al. This is an Open Access article distributed under the terms of the Creative Commons Attribution License (http://creativecommons.org/licenses/by/4.0), which permits unrestricted use, distribution, and reproduction in any medium, provided the original work is properly credited. 
among policy makers at quality assurance institutions. The rising concerns regarding the extent of plagiarism practiced by students worldwide, has promoted the research and publications on prevention, detection and deterrence of plagiarism in order to address various interrelated aspects.

Research on the contributing factors for plagiarism (Chanock 2008) and the deterrence mechanisms (Carroll \& Ryan 2005; Carroll 2007) have associated good practices on academic writing with anti-plagiarism approaches. A number of educational resources are published online or in hard copy which offers advice primarily to students and to academics willing to assist their students. These resources outline best practices that contribute towards prevention of plagiarism. Published educational resources include principles and examples of paraphrasing, referencing and properly addressing sources. Awareness of best practices, per se, is only a part of any policy aiming to prevent plagiarism. Repetitive practice of academic writing (Emerson et al. 2005) and proper examples have also been proposed in the framework of anti-plagiarism approaches.

Another relevant approach is the provision of feedback to students' work relative to plagiarism before final submission of the work (Barrett \& Malcolm, 2006). This can be accomplished as part of a formative assessment of students' work, which includes access to similarity reports of software packages that support identification of text similarities (Davis 2009). Ireland and English (2011) have proposed the concept of a "safe environment" where students are allowed to "plagiarise"; This does not suggest that plagiarism is encouraged; students are free to submit their work, get feedback on plagiarism issues they may have committed, address them and resubmit their work. It is viewed that through this iteration cycle they gradually develop proper academic writing skills. Such an approach was made possible as a result of the development of tools, such as Turnitin $\odot$, which aim to prevent and detect plagiarism via text-matching software and allow formative assessment (Bennett, 2005; Davis 2007; Murray, 2006).

Combating plagiarism effectively, while maintaining consistency in the standards and quality of higher education across the European Union (EU) requires the identification of any gaps, best practices and case studies relating to plagiarism across the member states. Research on practises and policies on anti-plagiarism at universities has been conducted primarily at English-speaking countries (McCabe 2005; Hayes and Introna 2005) and less so at non-English speaking institutions (McCabe et al. 2008; Carroll and Zetterling 2009). This paper reports on the findings of research conducted among university students in Cyprus HEIs as part of the "IPPHEAE: Impact of Policies for Plagiarism in Higher Education across Europe" ERASMUS-Lifelong Learning" project (2010-2013). The purpose of IPPHEAE research project was to establish how the issue of student plagiarism is addressed by Higher Educational Institutions (HEIs) across the European Economic Area. The IPPHEAE project (Web 1 http://www.ippheae.eu/ Last Accessed September 28th (2014) examined policies and procedures for detecting and handling cases of student plagiarism; the extent to which current policies and procedures were working; preventing measures against student plagiarism; how the relevant policies and procedures were determined, monitored, reviewed and updated and the perspectives of management, lecturers and students. In this paper we present the research findings that refer to students who study in HEIs in the Republic of Cyprus; this research focuses students' awareness and perceptions relating to academic plagiarism. More specifically, we discuss the methodology followed, some of the research findings and the points of future investigation. 


\section{Methods}

The research undertaken in the IPPHEAE project explored plagiarism-related aspects for three major stakeholders, high rank academics, teaching faculty and students at bachelor and master's degree level rather than doctoral, post-doctoral. Initially, the research instrument for students was designed based on the feedback received from the five partner institutions participating in the IPPHEAE project. A focus group of domain experts was used to further explore potential for improvement of the questions and for the content validity of the questionnaire. The original questionnaire was translated into the national languages of each partner organization project and pilot tested in each participating country, namely in UK, Poland, Lithuania, Czech Republic and Cyprus. IPPHEAE researchers were physically present during the pilot testing to observe the respondents' completion of the questionnaires and to provide guidance if required on interpretation. Based on the observations and received feedback, adjustments to wording were incorporated into the different language versions of the questionnaire. Further language translations and adjustments were then produced based on the final version of the English survey. In total 14 different language versions of the survey were created.

The questionnaire included 33 questions of the following types: i) open-ended questions; ii) multiple choice questions in two variations: those requiring mutually exclusive options and single response and those permitting multiple selected answers and iii) Likert-type scale questions. The survey instrument is available on the IPPHEAE web site (Web 1). Open ended questions were primarily used for testing knowledge (i.e. "Describe in one phrase or sentence what you understand by the word plagiarism") or soliciting feedback (i.e. "Please provide any suggestions or ideas on how to reduce student plagiarism"). Multiple choice questions were mainly used for exploring situational parameters, a typical example of a question in this category might be "What digital tools or other techniques are available at your institution for helping to detect plagiarism? (tick all that apply)". Likert-type scale questions were used to detect multi-dimensional constructs related to students' perceptions, intentions and past behaviour with regards to plagiarism (i.e. "I have come across a case of plagiarism committed by a student at this institution"). For Likert-type scale questions Cronbach's Alpha Reliability Coefficient was found to be satisfactory (Cronbach Alpha $=.716$ ). For the Likert-type scale questions, Cronbach's Alpha Reliability Coefficient was found to be satisfactory (Cronbach Alpha = .716).

The target population of the study included all students, undergraduate and graduate, pursuing an academic degree, in public and private universities in Cyprus. There was no restriction in terms of subject focus of survey participants. However, in order to ensure the limited resources of the project were not over-stretched the survey aimed to reach $10 \%$ of Higher Education Institution (HEIs) per country or at least one HEI in every country surveyed. In Cyprus, which is a small country island, the survey covered all three state Universities and three out of four private Universities. In addition, the survey targeted a representative sample of academic programs including applied sciences, engineering, social sciences, business and life science. This paper presents the findings from the analysis of selected questions (specifically questions 2,4,6,7,9,11,15,16,17,22,23,26,29, and 31) so as to address the purposes of this paper. A total of 318 correctly completed questionnaires were collected. Prizes, based on a lottery draw, were offered to students to encourage them to complete the questionnaire. 


\section{Results and discussion}

A variety of demographic data were collected, so as to enable other future research. With regards to the demographic variables of 'year of study' and 'age' it should be noted that there is no correspondence and no dependency between those variables. A student, for instance, can be forty years old and in his/her first year of study. In addition, the data collected from all three local Higher Education Institutions were not analysed separately but collectively. The reason for that was that because of the small, and highly competitive nature of the Cyprus higher Education market, the management of the Institutions allowed the distribution of the questionnaire and the publication of the findings based on the understating that the results will be presented collectively for all three institutions participating in the study. Finally, cross-tabulations of research is considered for future work.

As shown in Table 1 below, the majority of the respondents (74.7\%) were undergraduate students, studying on a full-time basis (81.5\%), in their last year of study (34.8\%) and between $21-25$ years old (55.4\%).

With regard to the definition of plagiarism, the three most popular answers (in terms of descending popularity) given by students were: "Copy and paste, without acknowledgement of the source you took your material from" $(\mathrm{N}=37)$; "Plagiarism is a close imitation or form of cheating" $(\mathrm{N}=16)$ and "The uses of work/research of others without citation, thus making it appear as your own work" $(\mathrm{N}=9)$. These definitions capture some of aspects of the plagiarism as defined, for example in (Carroll 2007), but fail to point to special cases (i.e. self-plagiarism) or nuances of plagiarism (i.e. unsuccessful paraphrasing). These results indicate a lack of a clear understanding of "plagiarism" as understood by students and this is in agreement with Carrolls' (2007) conclusions that students' perception of the term is not shared by universities or academicians.

Concerning the findings presented in tables and/or figures in this paper, is should be noted that findings expressed as percentages refer to questions with only one possible answer, whereas findings expressed in absolute numbers refer to questions where respondents had the opportunity to provide more than one answer.

As shown in Figure 1 below, there are no significant differences in the number of students who become aware of plagiarism either before $(41.1 \%)$ or during their undergraduate studies (39.5\%). However, the majority of students (70.8\%) appear to learn how to cite and reference only during their undergraduate studies.

The sources most frequently cited by students as those that provide them with information on plagiarism are the web $(\mathrm{N}=145)$ and courses booklets, student guide and handbooks $(\mathrm{N}=144)$. These two sources were also leading students' answers regarding awareness raising mechanisms for academic dishonesty deterrence. The above results suggest that

Table 1 Demographics: Cyprus data

\begin{tabular}{llllllll}
\hline \multirow{2}{*}{ Degree } & \multicolumn{7}{l}{ Percentage of total students responded $(\mathrm{n}=318)$} \\
\cline { 2 - 8 } & $\%$ & Mode of study & $\%$ & Year of study & $\%$ & Age (years) & $\%$ \\
\hline Bachelor's & 74.7 & Full time & 81.5 & First & 27.2 & $<20$ & 13.1 \\
Master's & 25.3 & Part time & 12.0 & Second & 17.0 & $21-25$ & 55.4 \\
PhD & 0 & Other & 6.5 & Third & 17.4 & $26-30$ & 9.6 \\
& & & & Fourth & 34.8 & $31-40$ & 16.9 \\
& & & & Fifth & 3.3 & $41-50$ & 4.8 \\
& & & & Sixth or higher & 0.3 & $50+$ & 0.3 \\
\hline
\end{tabular}




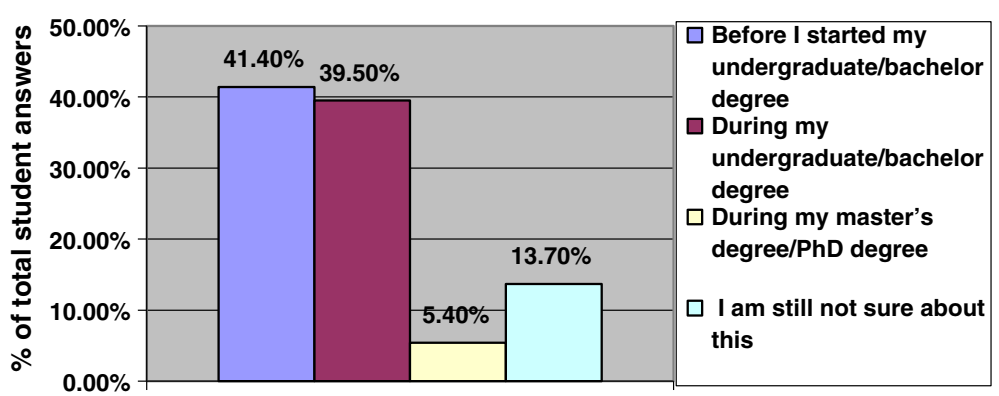

Figure 1 Timing of plagiarism awareness.

the period of university undergraduate training is an important period for sensitising students with regards to avoiding plagiarism and academic dishonesty.

As indicated from the results to the relevant question in Table 2 below, awareness of plagiarism may be part of the students receiving adequate training on academic writing and anti-plagiarism issues (70.8\% agree).

Although, on the basis of the questions used it was not evident how early the students receive such training, it was of interest to see that the majority of (70\%) received it from "tutors and lecturers and/or during a course/module (57.2\%) as shown in Table 3 below.

The findings presented in Table 3 suggest that having an institutional formal service to provide students with information and advice on how to avoid plagiarism may be an effective means of raising student awareness and preventing plagiarism.

The majority of students, $78.3 \%$ of them, knew that they would avoid being accused of plagiarism if they were to use the correct referencing and citation. This is in agreement with what the majority of students consider plagiarism and it would suggest that indeed teaching students about referencing/citing could be the right approach to reduce plagiarism. Of course, from the results, it shown in Figure 2, it does appear that the majority of students $(72 \%)$ use referencing and citation for promoting their own writing rather than for giving credit to the author(s) of the sourced material.

Table 4 raises an interesting point regarding the answers given by students when asked to identify six different cases of plagiarism that had been selected to represent fine distinctions of plagiarism with different levels of difficulty in their identification. For example, scenarios (c) and (f) could be construed as poor academic practice; however, they are presented within the context that a paper has a high degree of similarity to another work. The table also includes the answers given by faculty who were asked the same question in another survey, which was also conducted within the IPPHEAE project. It is commendable that the presented scenario (a) was correctly identified as plagiarism by the overwhelming majority of faculty and students. Moreover, both agreed by majority that such cases ought to be punished. The percentages of students and teachers who positively identifying possible plagiarism examples from the remaining options, particularly cases (c), (f) for students, was much lower. This would suggest that students' confidence in understanding academic writing conventions may be misplaced and that faculty may had plagiarized,

Table 2 Training received on scholarly academic writing and anti-plagiarism issues

\begin{tabular}{llllll}
\hline Strongly disagree & Disagree & Not sure & Agree & Strongly agree & Not applicable \\
\hline $2.2 \%$ & $11.1 \%$ & $10.5 \%$ & $47 \%$ & $23.8 \%$ & $5.4 \%$ \\
\hline
\end{tabular}


Table 3 Types of advising services conveying information on avoiding plagiarism

\begin{tabular}{ll}
\hline Services & Responses \\
\hline Academic support unit & 64 \\
Advice in class during course/module & 181 \\
Additional lectures or workshops & 80 \\
Advice from tutors or lecturers & 222 \\
Guidance from the Library & 99 \\
University publisher & 91 \\
\hline
\end{tabular}

unintentionally. There were differences between the two groups regarding the application of sanctions. The percentage of students opting for "sanctions" in cases (b-f) was significantly lower than those of teachers. The considerable percentage of teachers who failed to identify primarily case (d), but also cases (c, f) as plagiarism is worrying because the participants took part in this survey voluntarily, making it more likely that they are more informed and/or more sensitive on plagiarism issues.

These results confirm that students' understanding of what is considered to be plagiarism differs from that of faculty and needs to be addressed by some educative measures. Their inadequacy in understanding plagiarism is also reflected upon the reasons they state had lead them into citation and referencing. From the responses summarized in Figure 2, it is alarming to see the large percentage of students who think that the purpose of referencing and citation is to defend themselves against accusations of plagiarism or to give authority to their work. It is interesting to note that two students who selected the option "other" wrote "to prove the effort invested" and "to demonstrate the extent of the conducted work". It is commendable that the majority of students (202 out of 318) also recognized the importance of acknowledging the authors and crediting them with the originality of the work.

It is interesting to notice that, despite the level of difficulty in presented scenarios for plagiarism detection and the varying approached followed to deter plagiarism in different universities in Cyprus, we did not find any statistically important difference in plagiarism detection among students from different Universities with the exception of one scenario. More specifically, when students were presented with a scenario in which someone has copied part of a text, has changed a few words, has proper citation and correct references and were asked to decide if it is plagiarism or not, students from University 1 were more confident that the others that this was indeed plagiarism.

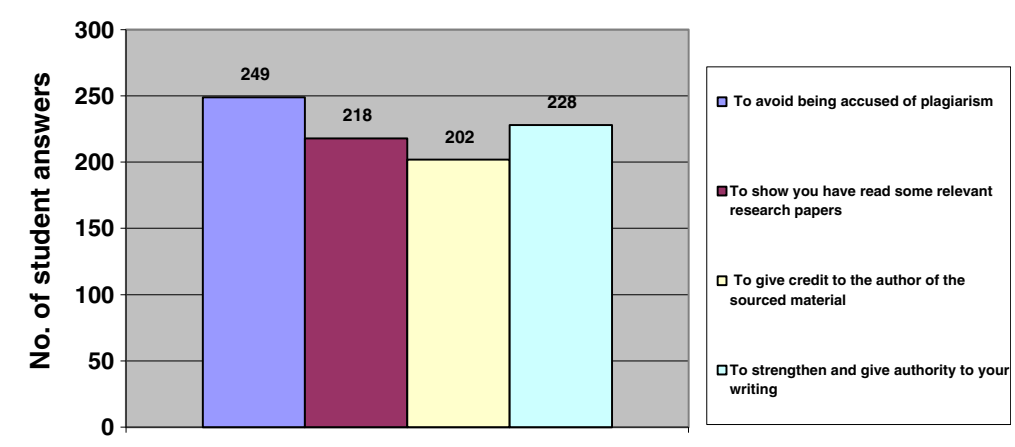

Figure 2 Reasons for using correct referencing and citation in scholarly academic writing. 
Table 4 Students' and teachers' ability to identify cases of plagiarism of varying degree of identification difficulty

\begin{tabular}{|c|c|c|c|c|c|}
\hline \multicolumn{6}{|c|}{ Students' responses to possible cases of plagiarism } \\
\hline \multirow[t]{2}{*}{$\overline{Q u}$} & \multicolumn{3}{|c|}{ Is it plagiarism? } & \multirow[t]{2}{*}{ Sanction? } & \multirow{2}{*}{$\begin{array}{l}\text { Assuming that } 40 \% \text { of a student's submission is from other } \\
\text { sources and is copied into the student's work as described } \\
\text { in (a-f) below, indicate your judgement on plagiarism }\end{array}$} \\
\hline & Yes & No & Don't know & & \\
\hline a & $90 \%$ & $3 \%$ & $7 \%$ & $82 \%$ & word for word with no quotations \\
\hline $\mathrm{b}$ & $74 \%$ & $5 \%$ & $21 \%$ & $58 \%$ & $\begin{array}{l}\text { word for word with no quotations, has a correct references but } \\
\text { no in text citations }\end{array}$ \\
\hline c & $44 \%$ & $24 \%$ & $33 \%$ & $29 \%$ & $\begin{array}{l}\text { word for word with no quotations, but has correct references } \\
\text { and in text citations }\end{array}$ \\
\hline d & $66 \%$ & $8 \%$ & $26 \%$ & $61 \%$ & $\begin{array}{l}\text { with some words changed with no quotations, references or } \\
\text { in text citations }\end{array}$ \\
\hline e & $56 \%$ & $9 \%$ & $35 \%$ & $51 \%$ & $\begin{array}{l}\text { with some words changed with no quotations, has correct } \\
\text { references but no in text citations }\end{array}$ \\
\hline f & $34 \%$ & $29 \%$ & $38 \%$ & $25 \%$ & $\begin{array}{l}\text { with some words changed with no quotations, but has correct } \\
\text { references and in text citations }\end{array}$ \\
\hline \multicolumn{6}{|c|}{ Teachers' responses to possible case of plagiarism } \\
\hline \multirow[t]{2}{*}{$\overline{Q u}$} & \multicolumn{3}{|c|}{ Is it plagiarism? } & \multirow[t]{2}{*}{ Sanction } & \multirow{2}{*}{$\begin{array}{l}\text { Assuming that } 40 \% \text { of a student's submission is from other } \\
\text { sources and is copied into the student's work as described } \\
\text { in (a-f) below, indicate your judgement on plagiarism }\end{array}$} \\
\hline & Yes & No & Don't know & & \\
\hline $\bar{a}$ & $100 \%$ & $0 \%$ & $0 \%$ & $93 \%$ & word for word with no quotations \\
\hline$b$ & $89 \%$ & $0 \%$ & $8 \%$ & $85 \%$ & $\begin{array}{l}\text { word for word with no quotations, has a correct references but } \\
\text { no in text citations }\end{array}$ \\
\hline C & $64 \%$ & $12 \%$ & $24 \%$ & $43 \%$ & $\begin{array}{l}\text { word for word with no quotations, but has correct references } \\
\text { and in text citations }\end{array}$ \\
\hline$d$ & $96 \%$ & $0 \%$ & $4 \%$ & $100 \%$ & $\begin{array}{l}\text { with some words changed with no quotations, references or } \\
\text { in text citations }\end{array}$ \\
\hline e & $84 \%$ & $8 \%$ & $8 \%$ & $71 \%$ & $\begin{array}{l}\text { with some words changed with no quotations, has correct } \\
\text { references but no in text citations }\end{array}$ \\
\hline$f$ & $44 \%$ & $28 \%$ & $28 \%$ & $36 \%$ & $\begin{array}{l}\text { with some words changed with no quotations, but has correct } \\
\text { references and in text citations }\end{array}$ \\
\hline
\end{tabular}

Looking now at the reasons for which students plagiarise as presented in Figure 3 below, the most popular answer (68.5\%) was "it is easy to copy and paste from the internet" followed by "they run out of time" (58.5\%) and "they think they will not get caught" (57.0\%). These results suggest that although students realize that plagiarism is wrong, and know how to cite and reference correctly, they resort to plagiarism because it is easy to do so if they run out of time, and because they feel that they are not going to

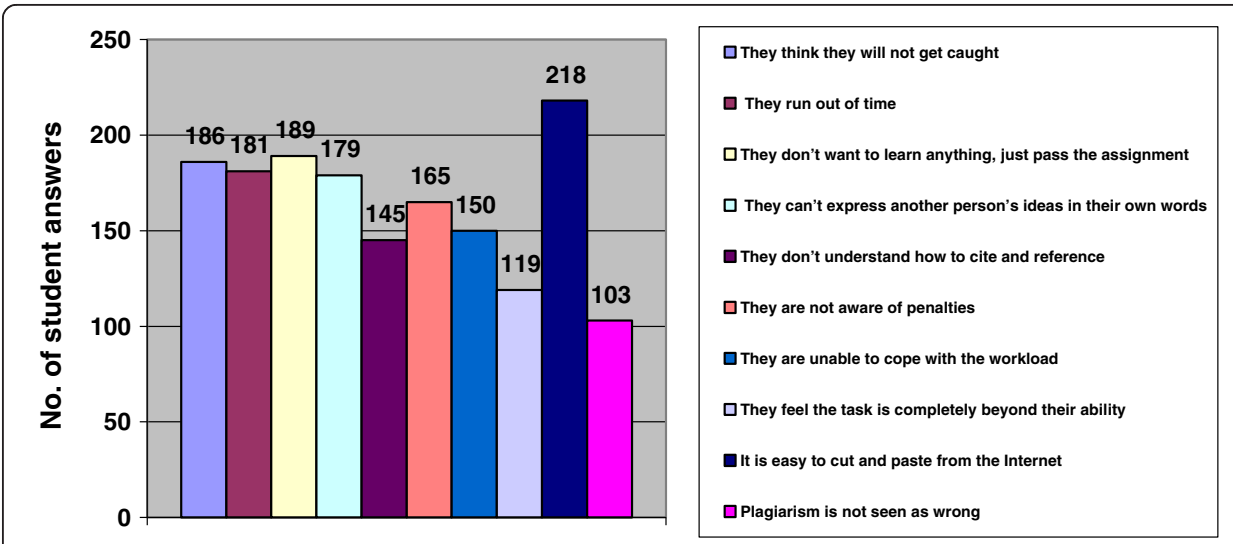

Figure 3 What leads students to decide to plagiarize? 
get caught. Preliminary studies on similar feedback from students who were introduced to the Turnitin software have indicated that the students are less likely to plagiarize if they are going to get caught. This suggests that the knowledge that plagiarism can be detected can be very effective in preventing plagiarism. Therefore, adjusting institutional policies and procedures with measures that are explicitly targeted to the leading driving forces of plagiarism renders them more effective.

Table 5 below presents the findings with respect to the existence of policies, procedures and penalties relating to plagiarism and academic dishonesty and with respect to communicating and implementing these within the Higher Education Institutions in Cyprus.

As Table 5 below indicates, the majority of students agree about the existence of policies and procedures for dealing with plagiarism and for dealing with academic dishonesty at their institution. However, only about one third of the students agreed that policies, procedures and information about penalties for plagiarism are available to them. Furthermore, a significant percentage of students were not sure how these policies apply, if all lecturers follow the same procedures for similar cases of plagiarism and if lecturers consistently treat similar cases of plagiarism. These findings suggest (a) that HEIs in Cyprus may not communicate clearly such important information to students, (b) that there may be inconsistency in the ways lecturers apply or follow such policies and procedures, and (c) that there are HEIs that may not always apply their plagiarism related procedures. We point out that in questions (h) and (d) differences in students' answers are statistically important and that students from University 5 have firm beliefs that their University has clear policies, procedures and penalties regarding academic dishonesty and plagiarism. Based on this finding, the communication policy followed by University 5 is proposed as a basis of reference for other Universities in Cyprus. Noteworthy are also the findings relating to what the penalties for student would be if found guilty of plagiarism, which are shown in Table 6. The most popular penalty proposed by students for plagiarising in assignments, was "zero mark for the exam" (51\%), followed by $48 \%$ for "verbal warnings"; whereas for a final project/thesis the most popular penalty was "request to re-write the work" (50\%) followed by "formal warning letter" (33.3\%). These findings indicate that students are willing to accept a more severe penalty for the types of student assessment that have less of an impact on their overall grade (i.e. assignment vs. thesis).

Our research on the digital tools or other techniques used for detecting plagiarism at the HEIs of Cyprus showed that during the course of this research there was very limited student awareness of any such software or technology-enabled techniques for detecting plagiarism. Students were asked to name what digital tools or other techniques are available at their institution for helping to detect plagiarism. About one third (111 out of 312 students) answered that they did not know that there is any such tool or technique, followed by those who guessed that their professors used the Internet or a search engine and the bibliography to locate plagiarism (22 out of the 312) and those that they said that professors use the software tools in the library to locate plagiarism (11 out of the 312). It is interesting to add that at the time of the research only two Universities had installed anti-plagiarism software. From the students who participated in our survey only 14 were able to name such software tools. This may be a contributing factor why "not getting caught" is the most popular reason for Cypriot students plagiarising. The lack of knowledge on the availability and effectiveness of such tools may also explain why this option was the last in the choices selected by Cypriot students as a means of reducing plagiarism. 
Table 5 Cross Tabulation of students and their ability to identify plagiarism among participating Universities in Cyprus

\begin{tabular}{|c|c|c|c|c|c|c|c|c|c|c|c|c|c|c|c|c|c|c|c|c|c|}
\hline \multirow{3}{*}{$\overrightarrow{{ }_{\#} \rightarrow \vec{n}}$} & \multirow{2}{*}{\multicolumn{5}{|c|}{$\begin{array}{l}\text { Plagiarism? } \\
\text { No Sanctions (\%) }\end{array}$}} & \multirow{2}{*}{\multicolumn{5}{|c|}{$\begin{array}{l}\text { Plagiarism? } \\
\text { Sanctions (\%) }\end{array}$}} & \multirow{2}{*}{\multicolumn{5}{|c|}{ Not Plagiarism (\%) }} & \multirow{2}{*}{\multicolumn{6}{|c|}{ Do not know (\%) }} \\
\hline & & & & & & & & & & & & & & & & & & & & & \\
\hline & 1 & 2 & 3 & 4 & 5 & 1 & 2 & 3 & 4 & 5 & 1 & 2 & 3 & 4 & 5 & 1 & 2 & 3 & 4 & 5 & \\
\hline \multirow[b]{2}{*}{ a } & $2,5 \%$ & $1,2 \%$ & $7,0 \%$ & $5,7 \%$ & & $7,4 \%$ & $8,6 \%$ & $14,0 \%$ & $7,5 \%$ & $2,8 \%$ & $24,7 \%$ & $30,9 \%$ & $39,5 \%$ & $26,4 \%$ & $31,9 \%$ & $65,4 \%$ & $59,3 \%$ & $39,5 \%$ & $60,4 \%$ & $65,3 \%$ & $\mathbf{X}^{2}=17,944$ \\
\hline & & & & & & & & & & & & & & & & & & & & & Sig $=, 117$ \\
\hline \multirow{2}{*}{ b } & $5,1 \%$ & $6,3 \%$ & & $5,8 \%$ & $4,4 \%$ & $20,3 \%$ & $13,9 \%$ & $31,8 \%$ & $36,5 \%$ & $14,7 \%$ & $55,7 \%$ & $54,4 \%$ & $52,3 \%$ & $44,2 \%$ & $61,8 \%$ & $19,0 \%$ & $25,3 \%$ & $15,9 \%$ & $13,5 \%$ & $19,1 \%$ & $\mathbf{X}^{2}=18,242$ \\
\hline & & & & & & & & & & & & & & & & & & & & & Sig $=, 109$ \\
\hline \multirow{2}{*}{ C } & $27,8 \%$ & $21,3 \%$ & $25,0 \%$ & $22,2 \%$ & $25,8 \%$ & $25,3 \%$ & $26,3 \%$ & $36,4 \%$ & $51,9 \%$ & $30,3 \%$ & $36,7 \%$ & $45,0 \%$ & $29,5 \%$ & $20,4 \%$ & $34,8 \%$ & $10,1 \%$ & $7,5 \%$ & $9,1 \%$ & $5,6 \%$ & $9,1 \%$ & $\mathbf{X}^{2}=16,624$ \\
\hline & & & & & & & & & & & & & & & & & & & & & Sig $=, 164$ \\
\hline \multirow{2}{*}{$\mathrm{d}$} & $12,5 \%$ & $7,4 \%$ & $6,8 \%$ & $9,3 \%$ & $4,5 \%$ & $22,5 \%$ & $25,9 \%$ & $31,8 \%$ & $24,1 \%$ & $28,4 \%$ & $41,3 \%$ & $44,4 \%$ & $45,5 \%$ & $48,1 \%$ & $43,3 \%$ & $23,8 \%$ & $22,2 \%$ & $15,9 \%$ & $18,5 \%$ & $23,9 \%$ & $X^{2}=5,933$ \\
\hline & & & & & & & & & & & & & & & & & & & & & Sig=,919 \\
\hline \multirow{2}{*}{ e } & $11,1 \%$ & $6,3 \%$ & $4,5 \%$ & $9,3 \%$ & $12,1 \%$ & $11,1 \%$ & $6,3 \%$ & $4,5 \%$ & $9,3 \%$ & $12,1 \%$ & $39,5 \%$ & $48,8 \%$ & $45,5 \%$ & $35,2 \%$ & $45,5 \%$ & $13,6 \%$ & $11,3 \%$ & $18,2 \%$ & $3,7 \%$ & $12,1 \%$ & $X^{2}=13,992$ \\
\hline & & & & & & & & & & & & & & & & & & & & & $\mathbf{S i g}=, 301$ \\
\hline \multirow{2}{*}{$f$} & $42,3 \%$ & $22,8 \%$ & $22,7 \%$ & $26,4 \%$ & $27,7 \%$ & $25,6 \%$ & $30,4 \%$ & $45,5 \%$ & $54,7 \%$ & $44,6 \%$ & $24,4 \%$ & $35,4 \%$ & $27,3 \%$ & $17,0 \%$ & $18,5 \%$ & $7,7 \%$ & $11,4 \%$ & $4,5 \%$ & $1,9 \%$ & $9,2 \%$ & $x^{2}=26,690$ \\
\hline & & & & & & & & & & & & & & & & & & & & & Sig $=, 009$ \\
\hline
\end{tabular}


Table 6 The outcome of being found guilty of plagiarism in their assignment or final project/dissertation

\begin{tabular}{lll}
\hline Penalty & Assignment & Final project \\
\hline No action would be taken & 52 & 29 \\
Verbal warning & 153 & 67 \\
Formal warning letter & 116 & 106 \\
Request to re write it properly & 133 & 159 \\
Zero mark for the work & 163 & 103 \\
Repeat the module or subject & 92 & 101 \\
\hline
\end{tabular}

\section{Conclusions/Recommendations}

According to our findings there is a lack of clear understanding among Cypriot university students regarding the definition of plagiarism. Cypriot universities need to bring about immediate improvements in plagiarism awareness so as to limit plagiarism and improve effectiveness in plagiarism policies and procedures developed and implemented, as well as in sanctions set, communicated and imposed. Specific recommendations that arise from the above conclusions to the benefit of the Universities and students, include: (a) inculcating students to the concepts of plagiarism, academic dishonesty and the idea of giving of credit to the rightful owner of the original work; (b) implementing in a consistent manner through faculty and audits the institutions' policies and procedures for the prevention of and the employment of sanctions against plagiarism; and (c) utilising plagiarism detection software to deter plagiarism and to enable students accomplishing proper academic writing. The HEIs in Cyprus have been established only recently (last 25 years) and are by majority under private rather than public governance. It would be of interest to see how the Cyprus results compare with those of Greece who have a much longer public university tradition, as well as with those from other EU countries. In fact this is the topic of a future research.

Competing interests

The authors declare that they have no competing interests.

Authors' information

Angelika I. Kokkinaki is Associate Professor and MBA Director in the School of Business, University of Nicosia. Angelika Kokkinaki's research interests include inter- and intra- organizational information systems. She has worked as a researcher and lecturer in USA, UK and the Netherlands. She has participated in many national and EU funded programs and has published over 70 articles and papers. She received her Ph.D. in Computer Science from the University of Louisiana at Lafayette (ULL), Lafayette, LA, USA, in 1995, her M.Sc. in Computer Science from Northeastern University, Boston, MA, USA in 1991 and a 5-year curriculum Diploma in Computer Engineering and Informatics from Patras University in 1987. She is a Chartered Engineer (Technical Chamber of Greece, 1987) and is an accredited Project Manager (MIT Professional Programs, 1998).

Catherine Demoliou is Professor of Biochemistry, Department of Life and Health Sciences, School of Sciences. Her research interests include biotechnology application for the production of plant derived antioxidants/anticancer drugs, PCR applications for the detection of animal species origin in food products, membrane receptor(s) function and signal transaction mechanisms and the molecular basis of cardiovascular diseases. During the period she served as a Dean of the School of Sciences she was responsible for reviewing and setting up QA policies/procedures as Dean (2001-2007). She is also a member of University of Nicosia QA-Committee and has been conducting QA for the accreditation of Bachelor of Science Programmes (7 years) Faculty of Computer Engineering, Computer Sciences, Electronics Engineering and of Life and Health Sciences of the University. She has published extensively and has led many national and EU funded projects. Melpo lacovidou holds a Doctorate in Quality Management from Middlesex University, UK, an M.B.A. from Adelphi University, USA and a B.Sc. from Indiana University of Pennsylvania, USA. Dr. lacovidou is an Assistant Professor and Head of the Office of Quality Assurance and Student Support at the University of Nicosia, Cyprus. She is also a member of the University Senate, member of the Internal Quality Assurance Committee, and the Internal Quality Assurance Auditor of the University of Nicosia. She was recently appointed as the Erasmus Institutional Coordinator. Dr lacovidou is a Project Team Member for the Industry Liaison Office and the Project Supervisor for the University of Nicosia. She has published in international journals and supervised successfully both undergraduate and graduate theses. Her areas of research interest include Quality Management and Service Quality as well as business ethics. 


\section{Acknowledgements}

Research reported in this paper has been funded by the project Impact of Policies for Plagiarism in Higher Education across Europe (IPPHEAE 510321-LLP-1-2010-1-UK-ERASMUS-EMHE). Authors are very grateful to all the project consortium partners for their cooperation in survey design and data collection, including: Coventry University (UK), Technical University of Lodz (Poland), Aleksandras Stulginkis University (Lithuania), Mendel University, Czech Republic

\section{Author details}

${ }^{1}$ Department of Management and MIS, University of Nicosia, Nicosia, Cyprus. ${ }^{2}$ Department of Life and Health Sciences, University of Nicosia, Nicosia, Cyprus. ${ }^{3}$ Department of Accounting, University of Nicosia, Nicosia, Cyprus.

Received: 1 August 2013 Accepted: 19 November 2014

Published online: 30 June 2015

\section{References}

Barrett R, Malcolm J (2006) Embedding plagiarism education in the assessment process. International Journal for Educational Integrity 2(2):38-45

Bennett R (2005) Factors associated with student plagiarism in a post-1992 university. Assessment and Evaluation in Higher Education 30(2):137-162

Carroll J (2007) A handbook for deterring plagiarism in higher education, 2nd edn. Oxford Brookes University, Oxford Centre for Staff and Learning Development, Oxford

Carroll J, Ryan J (2005) Teaching international students: Improving learning for all. Routledge, London

Carroll J, Zetterling C (2009) Guiding students away from plagiarism. KTH Learning Lab. http://people.kth.se/ ambe/ KTH/Guidingstudents.pdf [Accessed 12 June 2015]

Chanock K (2008) When students reference plagiarised materials - what can we learn (and what can we do) about their understanding of attribution? Int J Educ Integr 4(1):3-16

Davis M (2007) The role of Turnitin in the formative process of academic writing: A tool for learning and unlearning? Brookes e-Journal of Learning and Teaching, 2 (1). Available from: http://bejlt.brookes.ac.uk/article/the_role_of_ turnitin within the formative process of academic writing/ [Accessed 24 April 2013]

Davis, M (2009) The role of Turnitin within the formative process of EAP: a tool for global academic culture. BALEAP 2009 Conference Proceedings.

Emerson L, Rees M, MacKay B (2005) Scaffolding academic integrity: creating a learning context for teaching referencing skills. Journal of University Learning and Teaching Practice 2(3a):12-24

Hayes N, Introna LD (2005) Cultural values, plagiarism and fairness: when plagiarism gets in the way of learning. Journal of Ethics and Behaviour 15(3):213-223

Ireland C, English J (2011) Let them plagiarise: developing academic writing in a safe environment. Journal of Academic Writing 1(1):165-172

McCabe, DL (2005) Cheating amongst college students: A North American perspective. International Journal for Academic Integrity 1(1). Available from: http://www.ojs.unisa.edu.au/index.php/IJEl/article/view/14/9 [Accessed 24 April 2013

McCabe DL, Fenghali T, Abdallah H (2008) Academic dishonesty in the Middle East: individual and contextual factors. Res High Educ 5:451-467

Murray, W (2006) The plagiarism phenomenon. E.learning Age, 22-24. Available from: ABI/INFORM Global [Accessed 24 April 2013]

Web 1 http://www.ippheae.eu/ (Last Accessed September 28th 2014)

\section{Submit your manuscript to a SpringerOpen ${ }^{\circ}$} journal and benefit from:

- Convenient online submission

Rigorous peer review

- Immediate publication on acceptance

Open access: articles freely available online

- High visibility within the field

- Retaining the copyright to your article 